\title{
Klasifikasi Helpdesk Menggunakan Metode Support Vector Machine
}

\author{
Stefanie Hilda Kusumahadi ${ }^{1^{*}}$, Hartarto Junaedi ${ }^{2}$, Joan Santoso ${ }^{3}$ \\ ${ }^{1}$ Program Pascasarjana Teknologi Informasi, Sekolah Tinggi Teknik Surabaya, Surabaya \\ ${ }^{2}$ Departemen Sistem Informasi, Sekolah Tinggi Teknik Surabaya, Surabaya \\ ${ }^{3}$ Departemen Informatika, Sekolah Tinggi Teknik Surabaya, Surabaya \\ 1,2,3 Jln. Ngagel Jaya Tengah 73-77, Surabaya, 60284, Indonesia \\ email: 1stefaniehilda.jc@gmail.com, ${ }^{2}$ hartarto@stts.edu, ${ }_{3}^{3}$ joan@ @tts.edu
}

Copyright @2019, Politeknik Harapan Bersama, Tegal

\begin{abstract}
The online helpdesk with ticketing system with the help of operators often experiences problems such as inappropriate delegation processes, the duration of the helpdesk waiting time to be delegated, even the helpdesk is missed to be handled. The ticket delegation checked manually by the operator has risks creating an error in delegating helpdesk tickets to inappropriate technicians. The helpdesk classification system is needed so that every incoming helpdesk ticket can be classified to the right technician according to the job description. The incoming Helpdesk is classified into 6 types of requests, namely multimedia, documentation, internet, server, hardware, software and miscellaneous. This helpdesk grouping is needed so that related technicians for each helpdesk can work and help the helpdesk according to their respective job descriptions. The Support Vector Machine method is used to classify text on the helpdesk. The use of Linear and Polynomial kernels produces an accuracy of $78 \%$, the RBF or Gaussian kernel produces the highest accuracy of $81 \%$ while the Sigmoid kernel produces the smallest accuracy of $51 \%$. The helpdesk classification results with the Support Vector Machine method can produce quite good accuracy.
\end{abstract}

Abstrak - Helpdesk secara online dengan sistem ticketing dengan bantuan operator sering kali mengalami permasalahan seperti proses pendelegasian yang kurang tepat, lamanya waktu tunggu helpdesk didelegasikan, bahkan terlewatnya helpdesk untuk dapat ditangani. Proses delegasi tiket secara manual oleh operator beresiko menimbulkan terjadinya kesalahan pendelegasian tiket helpdesk kepada teknisi yang tidak sesuai. Sistem klasifikasi helpdesk dibutuhkan agar setiap tiket helpdesk yang masuk dapat diklasifikasikan dan didelegasikan ke teknisi yang tepat sesuai dengan job description. Helpdesk yang masuk diklasifikasi menjadi 6 macam permintaan bantuan yaitu multimedia, dokumentasi, internet, server, hardware, software. Pengelompokan helpdesk ini diperlukan agar teknisi terkait untuk masing-masing helpdesk dapat mengerjakan dan membantu helpdesk sesuai dengan job description masingmasing. Metode Support Vector Machine dipakai untuk melakukan klasifikasi teks pada helpdesk. Penggunaan kernel Linear dan Polynomial menghasilkan akurasi sebesar $78 \%$, kernel RBF atau Gaussian menghasilkan akurasi paling tinggi yaitu sebesar $81 \%$ sedangkan kernel Sigmoid menghasilkan akurasi paling kecil yaitu $51 \%$. Hasil klasifikasi helpdesk dengan metode Support Vector Machine dapat menghasilkan akurasi cukup baik.

*) Corresponding author: (Stefanie Hilda Kusumahadi)

Email: stefaniehilda.jc@gmail.com
Kata Kunci - Helpdesk, Support Vector Machine, Text Mining, Klasifikasi.

\section{PENDAHULUAN}

Proses delegasi tiket secara manual oleh operator beresiko menimbulkan terjadinya kesalahan pendelegasian tiket helpdesk kepada teknisi yang tidak sesuai. Apabila operator helpdesk terlewat melakukan pengecekan setiap tiket, maka akan dapat terjadi tiket helpdesk tidak dilayani sehingga dapat menimbulkan komplain dari user. Kinerja teknisi menjadi kurang efisien apabila harus menunggu pendelegasian manual dari operator helpdesk yang juga bisa melakukan kesalahan serta dapat terjadi delay/penundaan pekerjaan karena proses pendelegasian yang masih manual [1]. Pelayanan departemen IT pada suatu organisasi menjadi bagian penting untuk tetap menjaga perangkat keras dan perangkat lunak yang digunakan perusahaan berjalan dengan [2]. Oleh karena itu sistem klasifikasi tiket helpdesk dapat membantu proses pendelegasian secara otomatis kepada teknisi terkait sehingga tidak lagi memerlukan bantuan operator. Penelitian ini dapat membantu mengurangi kesalahan pendelegasian tiket helpdesk kepada teknisi di Yayasan Pendidikan Generasi Rajawali.

Helpdesk Yayasan Pendidikan Generasi Rajawali digunakan sebagai dataset penelitian yang berjumlah 2401 tiket. Metode yang digunakan adalah Support Vector Machine. SVM telah dikenal sebagai salah satu metode supervised machine learning yang baik untuk klasifikasi teks [3].

SVM telah sering digunakan dalam klasifikasi teks karena memiliki performa yang cukup baik dibandingkan dengan metode lainnya seperti Neural Network dan Naive Bayes. Sebagai contoh pada penelitian Mucahit Altintas dan A. Cuneyd Tantug untuk klasifikasi tiket helpdesk didapat akurasi tertinggi menggunakan SVM yaitu sebesar $90 \%$.

Pada penelitian ini dilakukan percobaan pada beberapa jenis kernel pada SVM untuk mengklasifikasikan tiket helpdesk yang belum ada pada penelitian terkait sebelumnya.

\section{PENELITIAN YANG TERKAIT}

Mucahit Altintas dan A. Cuneyd Tantug pada [1] melakukan penelitian terhadap tiket permintaan bantuan dengan sistem pendelegasian otomatis untuk mengurangi 
waktu tunggu operator tiket dalam melakukan delegasi secara manual serta mengurangi kesalahan dalam pendelegasian. Dilakukan pengklasifikasian terhadapat kategori tiket akan ditujukan kepada departemen yang mana, lalu diklasifikasikan kembali ke Sub kategori. Apabila prediksi memiliki angka confidence yang besar daripada threshold value, maka tiket akan diklasifikasikan pada kategori departemen dan sub kategori tersebut. Apabila nilai confidence tidak lebih besar dari threshold value, maka operator akan melakukan pendelegasian secara manual untuk tiket tersebut.

Klasifikasi pada penelitian ini menggunakan metode SVM dengan Kernel Polynomial karena dataset non linearly separable, Naive Bayes, $\mathrm{k}-\mathrm{NN}$ dengan nilai $\mathrm{k}=1$ dan Decision Tree. Hasil akurasi kategori departemen yang paling tinggi adalah metode SVM sebesar $90 \%$ untuk model pembobotan TF-IDF dan Boolean, $88 \%$ untuk model pembobotan TF. Untuk sub kategori, pada departemen Information Technology dengan model pembobotan TF-IDF dan classifier SVM menghasilkan akurasi paling tinggi yaitu $80 \%$, pada departemen Student Affairs dengan model pembobotan TFIDF dan classifier SVM menghasilkan akurasi paling tinggi yaitu $80 \%$ juga. Untuk departemen Health, Culture and Sport model pembobotan TF-IDF dan classifier Decision Tree menghasilkan akurasi 93\%. Pada departemen Office of Scholarships and Dormitories, Naive Bayes dan pembobotan TF menghasilkan akurasi paling tinggi yaitu $71 \%$. Untuk tingkat akurasi tidak dijelaskan penggunaan confusion matrix.

Goby Niklas, Brandt Tobias, Feuerriegel Stefan, Neumann Dirk pada [2] melakukan penelitian tiket terkait permasalahan IT. Text pada tiket dilakukan pre-processing dan diubah menjadi bentuk matrix atau document-term matrix. Matrix ini yang nantinya menjadi input algoritma. Peneliti membagi dataset menjadi $80 \%$ training set dan $20 \%$ testing set. Akurasi rata-rata untuk seluruh topik sebesar $92.72 \%$. sistem memiliki akurasi dan presisi lebih dari $85 \%$.

Dingding Wang, Tao Li, Shenghuo Zhu, Yihong Gong pada [4] membuat sistem helpdesk pintar dengan mencari kesamaan helpdesk yang masuk dengan histori helpdesk yang pernah ada, dari helpdesk lama kemudian dipelajari dan digunakan sebagai acuan menyelesaikan helpdesk yang baru. Harapannya agar penyelesaian helpdesk dapat dilakukan lebih cepat karena sudah pernah menyelesaikan kasus serupa. Penelitian ini mencari kesamaan kasus dengan sistem casebased dan perangkingan. Pada penelitian pencarian kemiripan helpdesk dihasilkan akurasi sebesar $72 \%$.

Support Vector Machine (SVM) adalah classifier binary yang dapat digunakan untuk klasifikasi teks multi kelas dengan memanfaatkan kernel. Adapun kelebihan SVM antara lain:

- Mampu mengolah data yang memiliki banyak fitur serta yang berdimensi tinggi dengan memanfaatkan fungsi $\Phi$ yang memetakkan data ke ruang vektor berdimensi tinggi atau high dimensional input space.

- Merupakan Classifier yang memberikan solusi bersifat global optimal atau solusi yang sama untuk setiap percobaan. SVM tidak memberikan solusi bersifat local optimal yang hasilnya berbeda untuk setiap percobaan.

Sedangkan kekurangan SVM adalah untuk klasifikasi lebih dari 2 kelas harus melakukan percobaan dengan beberapa Kernel untuk mendapatkan performa dari Kernel terbaik.
Pada penelitian klasifikasi teks helpdesk dilakukan percobaan pada beberapa jenis kernel SVM antara lain Kernel Linear, Kernel Polynomial, Kernel RBF, dan Kernel Sigmoid untuk mengklasifikasikan tiket helpdesk yang belum ada pada penelitian terkait sebelumnya. Dilakukan percobaan pada masing-masing kernel dengan parameter berbeda yang kemudian dibandingkan performanya dengan tujuan memperoleh performa terbaik nilai parameter dari setiap kernel.

\section{METODOLOGI PENELITIAN}

Alur proses penelitian yang dilakukan adalah seperti pada Gbr 1.

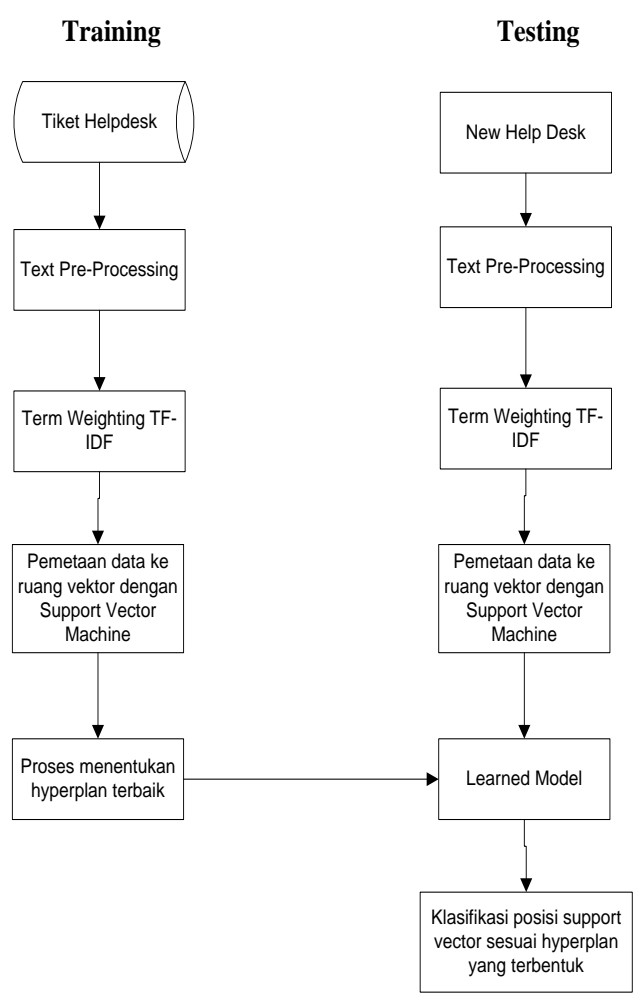

Gbr. 1 Alur Proses Klasifikasi Helpdesk

Proses klasifikasi tiket helpdesk dibagi menjadi 2 proses besar yaitu proses training dan proses testing. Pada proses training dan testing, dilakukan pre-processing terlebih dahulu pada tiket helpdesk. Setelah didapat kata-kata inti maka akan diberikan bobot dengan term weighting TF-IDF sehingga akan didapat nilai vector. Nilai vector kemudian diproses kedalam vector space. Support Vector Machine digunakan untuk mendapatkan hyperplane terbaik pada masing-masing kelas pada ruang vector.

\section{A. Preprocessing Untuk Mendapatkan Daftar Kata Dari Tiket Helpdesk}

Data helpdesk dari tahun 2014 hingga November 2018 dipakai menjadi dataset utama. Terlebih dahulu dilakukan preprocessing terhadapat dataset. Preprocessing dilakukan 6 tahap. Pada proses training dan testing, dilakukan preprocessing terlebih dahulu pada tiket helpdesk antara lain melakukan pengecekan bahasa helpdesk, apabila berbahasa inggris maka diterjemahkan terlebih dahulu ke bahasa 
indonesia, case folding atau mengubah huruf menjadi berukuran kecil, menghilangkan tanda baca dan angka, tokenisasi, stop word removal dan stemming. Stemmer sastrawi untuk bahasa Indonesia digunakan dalam proses stemming. Text pre-processing adalah tahapan penghilangan noise pada text sehingga menghasilkan output yang berupa bag-of word [5]. Tahap preprocessing ini meliputi:

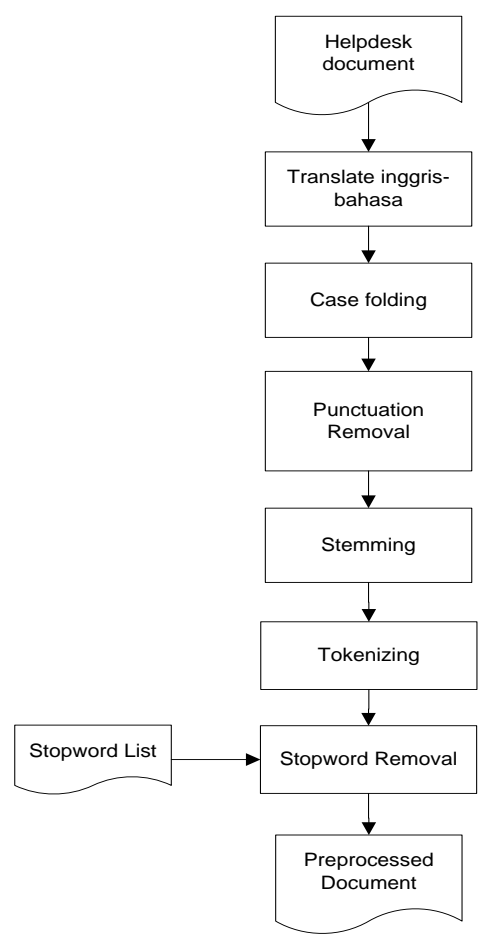

Gbr. 2 Alur Preprocessing

1) Case Folding: pada tahap ini isi teks yang terdiri dari huruf capital dan huruf kecil atau lower case diubah agar menjadi huruf kecil keseluruhan. Hal ini dilakukan agar teks menjadi seragam.

2) Tokenizing: pada tahap ini dilakukan pemotongan string berdasarkan tiap kata. Untuk karakter selain alfabet atau karakter tanda baca seperti whitespace, enter, tabulasi, spasi, petik tunggal ('), titik (.), semikolon (;), titik dua (:) dianggap sebagai pemisah kata. Selain itu tokenisasi juga membuang karakter-karakter tanda baca atau nonalfanumerik sehingga tersisa hanya sekumpulan kata-kata dari dalam dokumen.[6]

3) Stop Word Removal: merupakan tahap filtering yang adalah mengambil kata-kata penting dari hasil token serta membuang common word. Pada penelitian ini library stopword yang digunakan adalah Sastrawi. Algoritma stoplist (membuang kata kurang penting) atau wordlist (menyimpan kata penting). Stoplist/stopword adalah kata yang tidak deskriptif yang bisa jadi berupa kata penghubung yang tidak mendeskripsikan isi dari teks. Contoh dari stopwords adalah "yang", "dan", "di", "dari”dan seterusnya.

4) Stemming: tahap ini adalah proses mengubah kata yang berimbuhan menjadi kata dasar. Stemmer Sastrawi digunakan dalam penelitian ini untuk menghilangkan awalan dan akhiran. Proses stemming pada teks yang berbahasa Indonesia berbeda dengan proses stemming pada teks berbahasa Inggris karena teks berbahasa indonesia bisa mengandung awalan ataupun akhiran sedangkan teks berbahasa Inggris hanya ditambahkan akhhiran. Teks berbahasa Inggris diproses agar dapat menghilangkan sufiks. Sedangkan pada teks berbahasa Indonesia semua kata imbuhan baik itu sufiks dan prefiks juga dihilangkan pada proses stemming.

TABEL I

HASIL PREPROCESSING HELPDESK

\begin{tabular}{|c|c|c|c|c|}
\hline $\begin{array}{l}\text { Original } \\
\text { Request } \\
\text { Detail } \\
\end{array}$ & $\begin{array}{l}\text { Case } \\
\text { Folding }\end{array}$ & Stemming & Tokenizing & $\begin{array}{l}\text { Stop } \\
\text { Word } \\
\text { Removal } \\
\end{array}$ \\
\hline $\begin{array}{lr}\text { Tinta } & \text { Printer } \\
\text { Epson } & 850 \\
\text { yang } & \text { buat } \\
\text { print report. } & \text { Yang perlu di } \\
\text { refill, semua } \\
\text { warna, } \\
\text { soalnya sisa } \\
\text { sedikit } \\
\text { masing- } \\
\text { masing warna. } \\
\text { Thank you }\end{array}$ & $\begin{array}{l}\text { tinta } \\
\text { printer } \\
\text { epson } \\
850 \text { yang } \\
\text { buat print } \\
\text { report. } \\
\text { yang } \\
\text { perlu di } \\
\text { refill, } \\
\text { semua } \\
\text { warna, } \\
\text { soalnya } \\
\text { sisa } \\
\text { sedikit } \\
\text { masing- } \\
\text { masing } \\
\text { warna. } \\
\text { thank } \\
\text { you }\end{array}$ & \begin{tabular}{lr} 
tinta & printer \\
epson & 850 \\
yang & buat \\
print & report \\
yang & perlu di \\
refill & semua \\
warna & soal \\
sisa & sedikit \\
masing- \\
masing warna \\
\multicolumn{2}{l}{ thank you }
\end{tabular} & $\begin{array}{l}\text { tinta } \\
\text { printer } \\
\text { epson } \\
\text { yang } \\
\text { buat } \\
\text { print } \\
\text { report } \\
\text { yang } \\
\text { perlu } \\
\text { di } \\
\text { refill } \\
\text { semua } \\
\text { warna } \\
\text { soal } \\
\text { sisa } \\
\text { sedikit } \\
\text { masing } \\
\text { masing } \\
\text { warna } \\
\text { thank } \\
\text { you }\end{array}$ & $\begin{array}{l}\text { tinta } \\
\text { printer } \\
\text { epson } \\
\text { print } \\
\text { report } \\
\text { refill } \\
\text { warna } \\
\text { warna }\end{array}$ \\
\hline $\begin{array}{l}\text { Mohon } \\
\text { disediakan } \\
\text { voucher } \\
\text { internet untuk } \\
\text { hari ini ( } 31 \\
\text { Oct 2018) dari } \\
\text { jam 11.00 - } \\
14.00 \text { untuk } \\
26 \text { users. } \\
\text { Digunakan } \\
\text { untuk pembelajaran } \\
\text { matematika. }\end{array}$ & $\begin{array}{l}\text { mohon } \\
\text { disediaka } \\
\mathrm{n} \\
\text { voucher } \\
\text { internet } \\
\text { untuk } \\
\text { hari ini } \\
(31 \text { oct } \\
2018) \\
\text { dari jam } \\
11.00 \quad- \\
14.00 \\
\text { untuk } 26 \\
\text { users. } \\
\text { digunaka } \\
\mathrm{n} \text { untuk } \\
\text { pembelaj } \\
\text { aran } \\
\text { matemati } \\
\text { ka. }\end{array}$ & $\begin{array}{l}\text { mohon sedia } \\
\text { voucher } \\
\text { internet untuk } \\
\text { hari ini } 31 \text { oct } \\
2018 \text { dari jam } \\
1100-1400 \\
\text { untuk } 26 \text { users } \\
\text { guna untuk } \\
\text { ajar } \\
\text { matematika }\end{array}$ & $\begin{array}{l}\text { mohon } \\
\text { sedia } \\
\text { internet } \\
\text { untuk } \\
\text { hari } \\
\text { ini } \\
\text { oct } \\
\text { dari } \\
\text { jam } \\
\text { untuk } \\
\text { users } \\
\text { guna } \\
\text { untuk } \\
\text { ajar } \\
\text { matematika }\end{array}$ & $\begin{array}{l}\text { sedia } \\
\text { voucher } \\
\text { internet }\end{array}$ \\
\hline $\begin{array}{l}\text { MOHON } \\
\text { DIBANTU } \\
\text { UNTUK DI } \\
\text { ISI TINTA } \\
\text { PRINTER } \\
\text { HRD }\end{array}$ & $\begin{array}{l}\text { mohon } \\
\text { dibantu } \\
\text { untuk di } \\
\text { isi tinta } \\
\text { printer } \\
\text { hrd }\end{array}$ & $\begin{array}{l}\text { mohon bantu } \\
\text { untuk di refill } \\
\text { tinta printer } \\
\text { hrd }\end{array}$ & $\begin{array}{l}\text { mohon } \\
\text { bantu } \\
\text { untuk } \\
\text { di } \\
\text { isi } \\
\text { tinta } \\
\text { printer } \\
\text { hrd }\end{array}$ & $\begin{array}{l}\text { isi } \\
\text { tinta } \\
\text { printer } \\
\text { hrd }\end{array}$ \\
\hline
\end{tabular}

Tabel I menunjukkan hasil dari preprocessing terhadap text helpdesk. Hasil akhir yaitu pada kolom stop word removal akan diolah ke proses selanjutnya yaitu term weighting dengan menggunakan TF-IDF.

\section{B. Extraksi Fitur Hasil Preprocessing Menjadi Matriks dengan TF-IDF}

TF-IDF (Term Frequency Inverse Document Frequency) merupakan algoritma yang digunakan untuk menghitung bobot 
atau nilai frekuensi sebuah kata atau term di dalam sebuah dokumen dan juga dapat digunakan untuk menghitung bobot atau frekuensi di dalam banyak dokumen. Dalam model ruang vector, bobot dari term yang ada pada dokumen direpresentasikan oleh term-document matrix (atau termfrequency matrix) [7].

$$
\left[\begin{array}{ccccc} 
& T_{1} & T_{2} & \cdots & T_{t} \\
D_{1} & w_{11} & w_{21} & \cdots & w_{t 1} \\
D_{2} & w_{12} & w_{22} & \cdots & w_{t 2} \\
\vdots & \vdots & \vdots & \ddots & \vdots \\
D_{n} & w_{1 n} & w_{2 n} & \cdots & w_{t n}
\end{array}\right]
$$

Gbr 3. Contoh Matriks Term dari n - dokumen dan sejumlah t-term

Frekuensi kemunculan suatu term pada suatu dokumen disebut Term Frequency (TF) dengan formula seperti pada (1)

$$
T f=\left\{\begin{array}{c}
1+\log _{10}\left(f_{t, d}\right), f_{t, d}>0 \\
0, \quad f_{t, d}=0
\end{array}\right.
$$

Inverse Document Frequency (IDF) adalah jumlah dokumen dalam korpus dibagi jumlah dokumen yang mengandung term. Formula Inverse Document Frequency adalah seperti pada (2)

$$
I d f=\log \left(\frac{D}{d f_{j}}\right)
$$

Sehingga formula TF-IDF adalah penggabungan formula Term Frequency dengan Inverse Document Fequency dengan cara mengkalikan seperti pada (3)

$$
w_{i j}=T f * I d f
$$

\section{Klasifikasi Text Menggunakan Support Vector Machine}

Support Vector Machine adalah suatu algoritma yang dikembangkan oleh Boser, Guyon, Vapnik. Algoritma ini untuk pertama kalinya dipresentasikan ke publik pada tahun 1992 di Annual Workshop on Computational Learning Theory. Konsep dasar dari Support Vector Machine merupakan kombinasi dari teori-teori komputasi yang telah ada sebelumnya. Teori yang ada pada Support Vector Machine antara lain seperti margin hyperplane, kernel yang oleh Aronszajn dipresentasikan pada tahun 1950, demikian juga dengan konsep-konsep pendukung lainnya dari Support Vector Machine.[3] Algoritma SVM dapat menemukan hyperplane terbaik pada input space. Hyperplane adalah bidang pemisah suatu kelas dengan kelas lainnya. Prinsip dasar SVM adalah linear classifier yang berarti hanya bisa digunakan untuk mengklasifikasi data antara 2 kelas namun karena kasus pada dunia nyata umumnya adalah lebih dari 2 kelas maka dikembangkan lebih lanjut agar dapat bekerja pada masalah non-linear atau data non-linear dengan memasukkan konsep kernel trick dan menggunakan fungsi $\Phi$ agar dapat memetakkan data kedalam ruang berdimensi tinggi.

Pada penelitian ini library yang digunakan untuk implementasi metode Support Vector Machine adalah Library Linear SVC (Support Vector Classification) dan One Versus Rest. One Versus Rest adalah metode yang digunakan untuk multi klasifikasi yaitu klasifikasi lebih dari 2 kelas. Klasifikasi adalah suatu proses untuk menemukan model atau classifier yang memiliki performa terbaik sehingga mampu membedakan kelas dari data yang kemudian dilakukan prediksi kelas yang tidak diketahui dari suatu data lainnya.[8]

Masalah dalam dunia nyata umumnya bersifat non-linear separable atau tidak dapat dipisahkan secara linear oleh karena sebaran data yang beragam. Untuk menyelesaikan masalah non linearly separable problem, modifikasi metode SVM dilakukan dengan memasukkan fungsi Kernel.[9] [10]

1) Fungsi Kernel Linear

$$
K\left(x_{i}, x_{j}\right)=\left(x_{i}^{t} x_{j}\right)
$$

2) Fungsi Kernel Polynomial

$$
K\left(x_{i} \cdot x_{j}\right)=\left[\left(x_{i} \cdot x_{j}\right)+1\right]^{d}
$$

3) Fungsi Kernel Radial Basis Function (RBF)

$$
K\left(x_{i} \cdot x_{j}\right)=\exp \left(-\left\|x-x_{i}\right\|^{2} / 2 \sigma^{2}\right)
$$

4) Fungsi Kernel Sigmoid

$$
K\left(x_{i} \cdot x_{j}\right)=\tanh \left(\beta_{0} x_{i} \cdot x_{j}+\beta_{1}\right)
$$

Kernel trick memberikan berbagai kemudahan untuk memecahkan permasalahan non-linearly separable problem. Pada proses pembelajaran SVM, untuk menentukan support vector, cukup dengan melakukan percobaan pada beberapa fungsi kernel. Selanjutnya performa antara kernel dibandingkan agar didapatkan kernel dengan performa terbaik. Model yang telah dilatih akan melakukan klasifikasi terhadap data testing berdasarkan pengetahuan yang telah dipelajari sebelumnya dari proses training.

\section{Library Penunjang Aplikasi}

Pada penelitian ini menggunakan beberapa library pendukung dalam pembuatan aplikasi. Adapun detil kegunaan tiap library [11], [12]yang dipakai dijelaskan dalam tabel II berikut.

TABEL II

LIBRARY YANG DIGUNAKAN DALAM PENELITIAN

\begin{tabular}{|c|l|l|}
\hline No & \multicolumn{1}{|c|}{ Nama Library } & \multicolumn{1}{c|}{ Fungsi } \\
\hline 1 & sklearn.svm.LinearSVC & $\begin{array}{l}\text { library Linear } \\
\text { Support Vector } \\
\text { Classification }\end{array}$ \\
\hline 2 & sklearn.model_selection.Train_test_spilt & $\begin{array}{l}\text { library untuk } \\
\text { memisahkan } \\
\text { array atau } \\
\text { matrix menjadi } \\
\text { train dan test set }\end{array}$ \\
\hline 3 & sklearn.metrics.classification_report & $\begin{array}{l}\text { library evaluasi } \\
\text { classifier } \\
\text { dengan output } \\
\text { precision, recall, } \\
\text { f1 score dan } \\
\text { support }\end{array}$ \\
\hline 4 & sklearn.metrics.confusion_matrix & $\begin{array}{l}\text { library evaluasi } \\
\text { classifier } \\
\text { dengan output } \\
\text { confusion } \\
\text { matrix }\end{array}$ \\
& &
\end{tabular}


TABEL III

LIBRARY YANG DigUNAKAN DALAM PENELITIAN

\begin{tabular}{|c|c|c|}
\hline No & Nama Library & Fungsi \\
\hline 5 & sklearn.TfidfVectorizer & $\begin{array}{l}\text { library untuk } \\
\text { mengubah raw } \\
\text { document } \\
\text { menjadi matrix } \\
\text { dari TF-IDF }\end{array}$ \\
\hline 6 & sklearn.multiclass.OneVsRestClassifier & $\begin{array}{l}\text { klasifikasi } \\
\text { multiclass atau } \\
\text { multilabel dan } \\
\text { strateginya } \\
\text { terdiri dari } \\
\text { pemasangan } \\
\text { satu classifier } \\
\text { per kelas. } \\
\text { Untuk setiap } \\
\text { classifier, kelas } \\
\text { tersebut } \\
\text { dipasang } \\
\text { terhadap } \\
\text { semua kelas } \\
\text { lainnya. }\end{array}$ \\
\hline 7 & sklearn.preprocessing.label_binarize & $\begin{array}{l}\text { library untuk } \\
\text { mengubah } \\
\text { kelas ke dalam } \\
\text { bentuk binary }\end{array}$ \\
\hline 8 & Natural Language Toolkit (NLTK) & $\begin{array}{l}\text { sebuah } \\
\text { platform yang } \\
\text { digunakan } \\
\text { untuk } \\
\text { membangun } \\
\text { program } \\
\text { analisis teks. }\end{array}$ \\
\hline 9 & Sastrawi & $\begin{array}{l}\text { untuk } \\
\text { melakukan } \\
\text { stemming yaitu } \\
\text { menghilangkan } \\
\text { prefiks dan } \\
\text { sufiks pada } \\
\text { kata yang } \\
\text { berimbuhan } \\
\text { sehingga } \\
\text { kembali ke } \\
\text { bentuk } \\
\text { dasarnya. }\end{array}$ \\
\hline
\end{tabular}

\section{HASIL DAN PEMBAHASAN}

\section{A. Skema Penelitian}

Dataset helpdesk yang digunakan berjumlah total 2401 tiket. Tiket ini dari tahun 2014 hingga Oktober 2018. 70\% atau sebanyak 1680 tiket digunakan sebagai dataset training. 30\% atau 721 tiket digunakan untuk testing. Penelitian menggunakan scikit learn dengan libsvm sebagai tools yang dapat melakukan klasifikasi multi kelas dengan algoritma oneagainst-one. Scikit learn adalah modul berbasis Python yang mengintegrasikan machine learning algoritma permasalahan supervised dan unsupervised.[11]

Perhitungan performa dari suatu classifier dilakukan dengan menggunakan menggunakan confusion matrix. Dalam penelitian ini, Confusion matrix adalah alat yang berguna untuk menganalisis seberapa baik classifier dalam melakukan klasifikasi.[13]
TABEL IV

DATASET HELPDESK

\begin{tabular}{|c|c|c|}
\hline \multicolumn{3}{|c|}{ DATASET HELPDESK } \\
\hline 1 & Tipe & Total \\
\hline 2 & Multimedia & 751 \\
\hline 3 & Dokumentasi & 584 \\
\hline 4 & Server & 41 \\
\hline 5 & Internet & 110 \\
\hline 6 & Hardware & 713 \\
\hline Total Dataset Training & 202 \\
\hline \multicolumn{2}{|c|}{} \\
\hline
\end{tabular}

TP (true positif) dan TN (true negatif) memberikan informasi ketika classifier melakukan klasifikasi dengan benar, sedangkan FP (false positif) dan FN (false negatif) memberitahu ketika classifier melakukan kesalahan dalam klasifikasi. Dari confusion matrix didapatkan nilai :

$$
\begin{aligned}
& \text { Precision: } \frac{T P}{T P+F P} \\
& \text { Recall: } \frac{T P}{T P+F N} \\
& \text { Accuracy: } \frac{T P+T N}{T P+T N+F P+F N} \\
& \text { F1 Measure: } 2 \frac{\text { precision. recall }}{\text { precison + recall }}
\end{aligned}
$$

Tabel IV, V, VI, VII, VIII menunjukkan penggunaan confusion matrix sehingga didapatkan nilai precision, recall, accuracy, F1 Score dari masing-masing percobaan.

\section{B. Hasil Percobaan}

Percobaan pada tiap kernel yang berbeda dilakukan dengan menggunakan parameter dari angka terkecil hingga terbesar hingga didapat akurasi yang terbaik. Nilai parameter mengacu dari beberapa penelitian terkait yaitu [8][14].

Masing-masing kelas yaitu dokumentasi, hardware, Internet, Multimedia, Server, Software dihitung precision dan recall. Detil klasifikasi masing-masing kelas pada kernel linear adalah seperti pada tabel $\mathrm{V}$.

TABEL V

HASIL TESTING KERNEL LINEAR

\begin{tabular}{|c|c|c|c|c|}
\hline $\begin{array}{c}\text { Kernel } \\
\text { Linear }\end{array}$ & Precision & Recall & F1-Score & Support \\
\hline Dokumentasi & 0.77 & 0.74 & 0.76 & 173 \\
\hline Hardware & 0.77 & 0.87 & 0.82 & 208 \\
\hline Internet & 0.91 & 0.54 & 0.68 & 37 \\
\hline Multimedia & 0.78 & 0.92 & 0.84 & 236 \\
\hline Server & 1 & 0.17 & 0.29 & 12 \\
\hline Software & 0.71 & 0.22 & 0.33 & 55 \\
\hline
\end{tabular}

Percobaan menggunakan kernel linear menghasilkan akurasi sebesar $78 \%$ dengan nilai parameter terbaik yaitu $\mathrm{C}=$ 1. Kelas server memiliki nilai precision terbaik yaitu 1 namun nilai recall nya paling rendah yaitu 0.17 . Kelas multimedia 
memiliki precision 0.78 , dengan recall tertinggi sebesar 0.92 dan F1 score tertinggi yaitu 0.84 .

TABEL VI

HASIL TESTING KERNEL POLYNOMIAL

\begin{tabular}{|c|c|c|c|c|}
\hline $\begin{array}{c}\text { Kernel } \\
\text { Polynomial }\end{array}$ & Precision & Recall & F1-Score & Support \\
\hline Dokumentasi & 0.77 & 0.77 & 0.77 & 175 \\
\hline Hardware & 0.82 & 0.83 & 0.83 & 235 \\
\hline Internet & 0.83 & 0.76 & 0.79 & 25 \\
\hline Multimedia & 0.82 & 0.85 & 0.84 & 219 \\
\hline Server & 0.57 & 0.44 & 0.50 & 9 \\
\hline Software & 0.50 & 0.41 & 0.45 & 58 \\
\hline
\end{tabular}

Percobaan menggunakan kernel polynomial menghasilkan akurasi sebesar $78 \%$ dengan nilai parameter terbaik yaitu $\mathrm{C}=$ 1 , nilai $\mathrm{r}$ dan $\mathrm{d}$ adalah 10 . Kelas internet memiliki precision tertinggi yaitu 0.83 dengan recall 0.76 . kelas multimedia memiliki precision 0.82 dengan recall tertinggi yaitu 0.85 dan F1 score tertinggi 0.84 .

TABEL VII

HASIL TESTING KERNEL RBF

\begin{tabular}{|c|c|c|c|c|}
\hline Kernel RBF & Precision & Recall & F1-Score & Support \\
\hline Dokumentasi & 0.83 & 0.88 & 0.85 & 155 \\
\hline Hardware & 0.78 & 0.89 & 0.83 & 215 \\
\hline Internet & 1 & 0.44 & 0.61 & 41 \\
\hline Multimedia & 0.83 & 0.89 & 0.86 & 239 \\
\hline Server & 1 & 0.38 & 0.55 & 8 \\
\hline Software & 0.74 & 0.41 & 0.53 & 63 \\
\hline
\end{tabular}

Percobaan menggunakan kernel RBF atau Gaussian menghasilkan akurasi sebesar $81 \%$ dengan nilai parameter terbaik yaitu $\mathrm{C}=1$ dan $\gamma=10$. Kelas internet memiliki nilai precision tertinggi sebesar 1 dengan recall 0.44 . kelas multimedia memiliki nilai precision sebesar 0.83 dan recall tertinggi yaitu 0.89 dan F1 score sebesar 0.86 .

TABEL VIII

HASIL TESTING KERNEL SIGMOID

\begin{tabular}{|c|c|c|c|c|}
\hline $\begin{array}{c}\text { Kernel } \\
\text { Sigmoid }\end{array}$ & Precision & Recall & F1-Score & Support \\
\hline Dokumentasi & 0 & 0 & 0 & 189 \\
\hline Hardware & 0.80 & 0.74 & 0.77 & 213 \\
\hline Internet & 0 & 0 & 0 & 29 \\
\hline Multimedia & 0.40 & 0.94 & 0.56 & 222 \\
\hline Server & 0 & 0 & 0 & 7 \\
\hline Software & 0 & 0 & 0 & 61 \\
\hline
\end{tabular}

Percobaan menggunakan kernel Sigmoid menghasilkan akurasi sebesar $51 \%$ dengan nilai parameter terbaik yaitu $\mathrm{C}=$ $1, \mathrm{r}=0.01$. kelas hardware memiliki nilai precision sebesar 0.80 dan recall 0.74 serta F1 score 0.77 .

Kernel RBF atau Gaussian dapat memberikan akurasi tertinggi yaitu sebesar $81 \%$. Perbandingan akurasi dari masingmasing kernel seperti pada tabel IX.
TABEL IX

AKURASI TERTINGGI MASING-MASING KERNEL DAN PARAMETERNYA
\begin{tabular}{|l|c|c|c|c|c|}
\hline \multirow{2}{*}{$\begin{array}{l}\text { Kernel } \\
\text { Function }\end{array}$} & \multicolumn{4}{|c|}{ Optimization Parameter } & \multirow{2}{*}{ Akurasi } \\
\cline { 2 - 5 } & C & $\gamma$ & r & d & \\
\hline Linear & 1 & - & - & - & 0.78 \\
\hline $\begin{array}{l}\text { RBF } \\
\text { Gaussian }\end{array}$ & 1 & 10 & - & - & 0.81 \\
\hline Polynomial & 1 & - & 10 & 10 & 0.78 \\
\hline Sigmoid & 1 & - & 0,01 & - & 0.51 \\
\hline
\end{tabular}

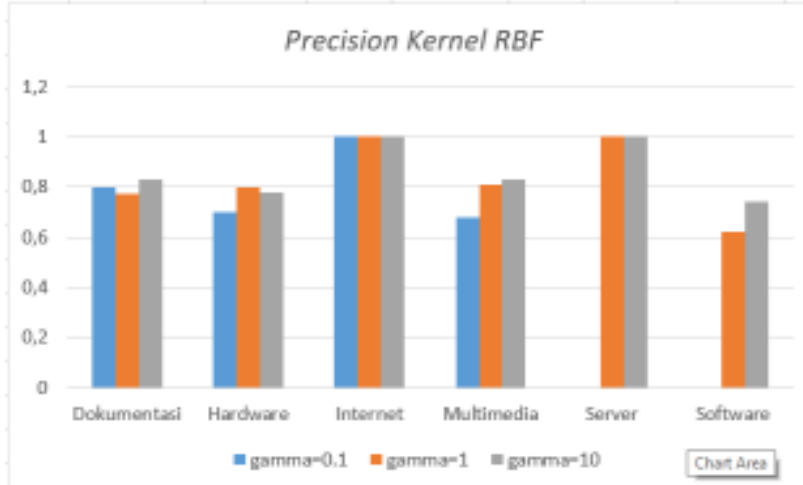

Gbr. 3 Perbandingan nilai precision percobaan nilai parameter kernel RBF/Gaussian

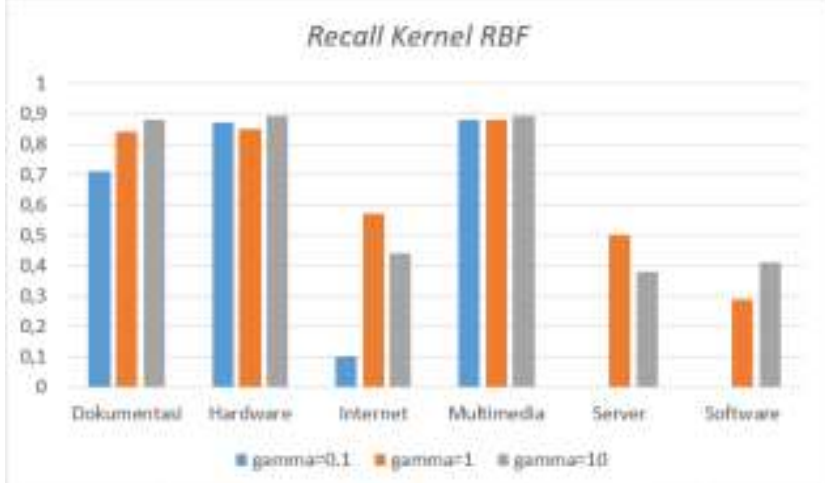

Gbr. 4 Perbandingan nilai recall percobaan nilai parameter kernel $\mathrm{RBF} /$ Gaussian

\section{F1 Score Kernel RBF}

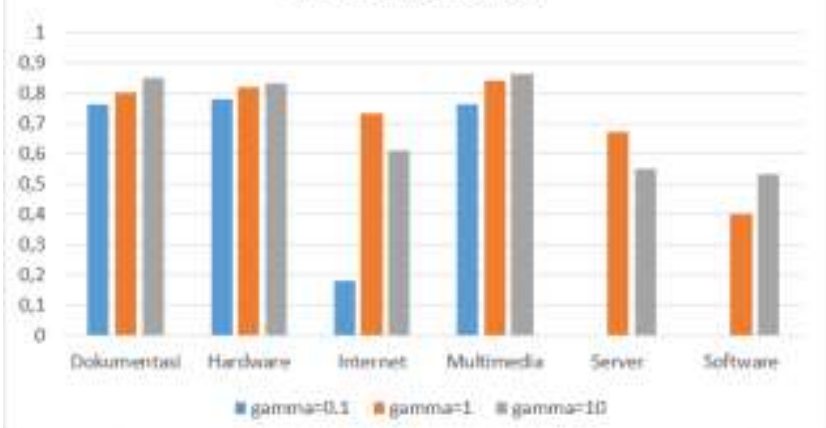

Gbr.5 Perbandingan nilai F1 score percobaan nilai parameter kernel RBF/Gaussian

Perbandingan nilai parameter kernel RBF atau Gaussian pada gambar 3 menunjukan perbandingan nilai precision dari paramater Gamma dengan nilai 0,1, 1 dan 10. Nilai Gamma=10 memberikan nilai precision lebih baik dari pada 0,1 atau 1. 
Perbandingan nilai recall dan F1 score pada nilai parameter Gamma $=10$ memberikan nilai yang lebih baik daripada nilai 0.1 atau 1 .

\section{KESIMPULAN}

Metode Support Vector Machine dapat digunakan untuk melakukan klasifikasi tiket helpdesk. Penggunaan kernel Linear dengan nilai parameter $\mathrm{C}=1$ menghasilkan akurasi sebesar 78\%. Kernel Polynomial dengan nilai parameter $\mathrm{C}=1$, $\mathrm{r}=10, \mathrm{~d}=10$ dapat menghasilkan akurasi sebesar $78 \%$. Penggunaan kernel Linear dan kernel Polynomial menghasilkan akurasi yang sama. Parameter $\mathrm{C}$ secara default pada fungsi kernel library scikit bernilai 1 dan dapat memberi akurasi tinggi.

Kernel RBF atau Gaussian menghasilkan akurasi paling tinggi yaitu sebesar $81 \%$ dengan parameter $\mathrm{C}=1$ dan $\gamma=10$. Kernel sigmoid menghasilkan akurasi paling rendah yaitu sebesar $51 \%$ dengan parameter $\mathrm{C}=1$ dan $\mathrm{r}=0.01$. Kernel Gaussian dengan parameter Gamma $=10$ menghasilkan akurasi paling tinggi dibandingkan dengan parameter Gamma lainnya.

Pada penelitian mendatang, akan dicoba untuk menerapkan algoritma Latent Semantic Indexing pada output TF-IDF sehingga proses ekstraksi fitur dapat menghasilkan fitur yang lebih baik untuk kemudian dipakai pada Model Support Vector Machine. Untuk mendapatkan akurasi lebih tinggi juga dapat dilakukan penyaringan kata terhadap bag of word dengan menambah daftar stopword serta penggunaan cross validation[15] dimana dataset dibagi menjadi test set, train set dan validation set.

\section{UCAPAN TERIMA KASIH}

Ucapan terima kasih penulis tujukan kepada dosen pembimbing dan dosen co pembimbing Sekolah Tinggi Teknik Surabaya serta rekan-rekan di Yayasan Pendidikan Generasi Rajawali yang telah memberikan dukungan dalam bentuk saran, pengetahuan dan data hingga terselesaikannya penelitian ini.

\section{DAFTAR PUSTAKA}

[1] M. Altintas and A. C. Tantug, "Machine Learning Based Tiket Classification in Issue Tracking Systems," Proceeding Int. Conf. Artif. Intell. Comput. Sci. (AICS 2014), no. September, pp. 195-207, 2014.

[2] N. Goby, T. Brandt, S. Feuerriegel, D. Neumann, and C. Research Goby, "Business Intelligence for Business Processes: the Case of It Incident Management," ECIS Proc., no. April, pp. 1-15, 2016.

[3] I. Pilászy, "Text Categorization and Support Vector Machines," vol. 1, pp. 1-10, 2004.

[4] D. Wang, T. Li, S. Zhu, and Y. Gong, "IHelp: An intelligent online helpdesk system," IEEE Trans. Syst. Man, Cybern. Part B Cybern., vol. 41, no. 1, pp. 173-182, 2011.

[5] Informatikalogi, "Text Preprocessing," 2016. [Online]. Available: https://informatikalogi.com/text-preprocessing/. [Accessed: 05-Dec2018].

[6] J. Santoso et al., "Self-Training Naive Bayes Berbasis Word2Vec untuk Kategorisasi Berita Bahasa Indonesia," JNTETI, vol. 7, no. 2, pp. 158166, 2018.

[7] K. J. Cios, W. Pedrycz, R. W. Swiniarski, and L. A. Kurgan, Data Mining A Knowledge Discovery Approach, vol. 30, no. 11. 2007.

[8] R. Munawarah, O. Soesanto, and M. R. Faisal, "Penerapan Metode Support Vector Machine Pada Diagnosa Hepatitis," Kumpul. J. Ilmu Komput., vol. 04, no. 01, pp. 103-113, 2013.

[9] A. S. Nugroho, A. B. Witarto, and D. Handoko, "Support Vector Machine , Teori dan Aplikasinya dalam Bioinformatika," Wiley Interdiscip. Rev. Comput. Stat., vol. 3, no. 3, pp. 204-215, 2011.

[10] S. Lee and H. BYUN, "A survey on pattern recognition applications of support vector machines," Int. J. Pattern Recognit., vol. 17, no. 3, pp. 459-486, 2003.

[11] É. D. Fabian Pedregosa, Gaël Varoquaux, Alexandre Gramfort, Vincent Michel, Bertrand Thirion, Olivier Grisel, Mathieu Blondel, Peter Prettenhofer, Ron Weiss, Vincent Dubourg, Jake Vanderplas, Alexandre Passos, David Cournapeau, Matthieu Brucher, Matthieu Perrot, "Scikit-learn: Machine Learning in Python," 2011. [Online]. Available: $\quad$ https://scikitlearn.org/stable/modules/generated/sklearn.svm.SVC.html.

[12] V. Pedregosa, F. and Varoquaux, G. and Gramfort, A. and Michel, P. and Thirion, B. and Grisel, O. and Blondel, M. and Prettenhofer, A. and and Weiss, R. and Dubourg, V. and Vanderplas, J. and Passos, and E. Cournapeau, D. and Brucher, M. and Perrot, M. and Duchesnay, "Scikit Learn: Support Vector Machine." [Online]. Available: https://scikitlearn.org/stable/modules/svm.html. [Accessed: 14-Jan-2019].

[13] J. Han, M. Kamber, and J. Pei, Data Mining Concepts and Techniques. 2011.

[14] R. Diani, U. N. Wisesty, and A. Aditsania, "Analisis Pengaruh Kernel Support Vector Machine ( SVM ) pada Klasifikasi Data Microarray untuk Deteksi Kanker," Ind. J. Comput., vol. 2, pp. 109-118, 2017.

[15] Antoni Wibowo, "10 Fold-Cross Validation," 2017. [Online]. Available: https://mti.binus.ac.id/2017/11/24/10-fold-cross-validation/. [Accessed: 16-Nov-2018]. 